\title{
IASON - FOSTERING SUSTAINABILITY AND UPTAKE OF RESEARCH RESULTS THROUGH NETWORKING ACTIVITIES IN BLACK SEA \& MEDITERRANEAN AREAS
}

\author{
P. Patias
}

The Aristotle University of Thessaloniki, GR, patias@auth.gr

Commission VII

KEY WORDS: Earth Observation, climate change, Mediterranean, Black Sea, EU

\begin{abstract}
:
IASON Project has the ultimate goal to establish a permanent and sustainable Network of scientific and non-scientific institutions, stakeholders and private sector enterprises belonging in the EU and third countries located in two significant areas: The Mediterranean and the Black Sea regions. The main focal points of the project will be the usage and application of Earth Observation (EO) in the following topics:

o climate change

0 resource efficiency

0 raw materials management

IASON aims to build on the experiences gained by 5 FP7 funded projects, OBSERVE, enviroGRIDS, GEONETCab, EGIDA, and BalkanGEONet. All of the above projects focused on enhancing EO capacities, knowledge and technology in the EU and in neighborhood countries. During their execution time they managed to establish links with a critical mass of research institutions, organizations, public organizations, stakeholders, and policy makers in the Balkan region, the Mediterranean, and the Black Sea Basin. IASON intends to create the proper conditions for enhancing knowledge transfer capacity building, and market opportunities in using EO applications and mechanisms in specific research fields that are addressing climate actions resource efficiency and raw materials management.
\end{abstract}

\section{INTRODUCTION}

\subsection{Concept and Objectives}

IASON Project has the ultimate goal to establish a permanent and sustainable Network of scientific and non-scientific institutions, stakeholders and private sector enterprises belonging in the EU and third countries located in two significant areas: The Mediterranean and the Black Sea regions. The main focal points of the project will be the usage and application of Earth Observation (EO) in the following topics:

- Actions to address climate changes

- Research and innovation to improve resource efficiency

- Raw Material Management

Land use, land cover and land monitoring are amongst the most important geographic information issues today. Their use is essential for climate variables, climate change monitoring, resources monitoring and estimation, detection of possible mining and drilling sites, detection and monitoring of environmental implications of mining and drilling activities, along with numerous other uses and applications. These had lead different organizations at regional, national, continental and world level to launch various Land Use and Land Cover information programmes: Corine Land Cover, GMES Land services, Globcove, to name but a few.

In a context were environmental threats (e.g. climate change in the form of sea level rise, water pollution, water and soil management, mining environmental implications, biodiversity loss, and food security) become more and more global, there is a need for better integration of various sources of information at different scales. Many activities producing information from global to local scale, as well as different research approaches to tackle these problems, are addressing specific requirements along with regional needs. This has resulted in a suite of different data and information that are not always compatible with each other.

IASON aims to build on the experiences gained by 5 FP7 funded projects, OBSERVE, enviroGRIDS, GEONETCab, EGIDA, and BalkanGEONet. All of the above projects focused on enhancing EO capacities, knowledge and technology in the Broader EU Region. Furthermore during their execution time they managed to establish links with a critical mass of research institutions, organizations, public organizations, stakeholders, and policy makers in the Balkan region, the Mediterranean, and the Black Sea Basin. The coordinators of these projects are members of the IASON consortium.

In addition, IASON creates links and collaborates with a number of on-going projects with similar aims, such as EOPOWER, MEDINA, RECREATE, ENSOCIO-LA, SUSTAIN EU-AESEAN, further capitalizing thus its activities (Figure 1).

IASON intends to create the proper conditions for knowledge transfer, capacity building and sustainable economic development through the use of EO applications and mechanisms in specific research fields that are addressing climate actions, research and innovation to improve resource efficiency and raw materials management. 




Figure 1. The IASON Network

In order to achieve its goal IASON engages in:

- Visible and effective capacity building and knowledge transfer activities with regional research institutes and organizations, stakeholders and policy makers.

- Demonstration of economic development through uptake of results, best case scenarios and success stories.

- Quantifiable engagement of research institutes, projects and networks.

- Identification of projects in the thematic fields that have potential for future cooperation.

- Creation of an innovative web based common information platform with clustering projects that demonstrate synergy potential.

In order to achieve the aforementioned goal, IASON network set the following objectives:

- Record, map, and categorize thematically and geographically scientific output achieved by regional and $\mathrm{EU}$ funded research creating a portfolio of existing prominent results.

- Capacity Building through data integration and interoperability.

- To asses projects results and their applications in the Mediterranean and Black Sea Regions under the three thematic nodes (coastal monitoring, water and soil resources management, and mining and mineral exploration).

- Establish an EO network covering the Mediterranean and Black Sea basins.

- Engage in activities that will foster cooperation between the network's members/countries and in particular between the EU and the non-EU members/countries on recorded gaps.

- Provide consultations to and develop firm links with regional and local institutions, stakeholders and policy makers bridging research agendas with EU priorities for 2020.

- Develop a toolkit for fostering and promoting access of regional research institutions to funding opportunities towards a sustainable and market oriented uptake of research results.

- Create and maintain thematic nodes of stakeholder communities that will act as focal points for future research interactions.

\subsection{The IASON Consortium}

The IASON consortium consists of 13 partners, from 12 different countries, namely: Albania, Croatia, Cyprus, Georgia, Greece, Italy, Morocco, Netherlands, Romania, Serbia, Switzerland, and Turkey. Five partners of IASON consortium are Universities, four partners are Research Centres / Institutes, and four partners are SMEs (Figure 2).

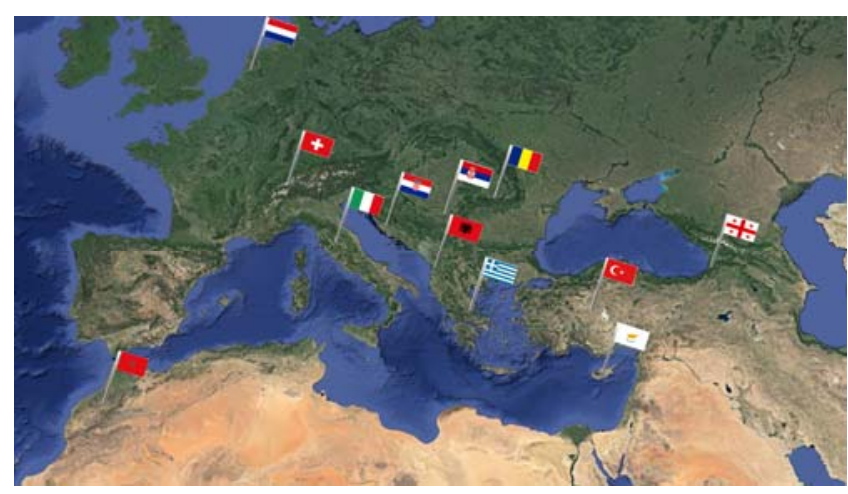

Figure 2. IASON consortium partners

The IASON consortium represents diverse and complementary expertises and skills that create a collective commensurate with the proposed project objectives. IASON consortium has experience in the participation and management of collaborative projects and coordination actions and some of the consortium members have already collaborated in the past with each other, a fact that ensures higher levels of understanding and efficiency.

\section{WORK PLAN AND CURRENT MAIN ACTIVITIES}

\subsection{Assessment of existing and on-going research efforts in the Mediterranean and Black Sea}

The main outcome of this activity is the creation of a portfolio of existing prominent results, and existing thematic networks, 
clustered along the three thematic priorities and the two regions of interest. In specific the objectives are:

- Review and analyse the current status, of coastal monitoring, water and soil management, and mining and mineral exploration with respect to EO applications.

- Network Mapping and Clustering of results.

- Identify, categorize and record all relevant stakeholders and users into a common reference platform database, setting the foundation for the formulation of a Mediterranean and Black Sea Network.

- Devise a tailor made networking and collaboration strategy of capacity building and technology transfer according to the specific EO needs of the three major challenges (coastal monitoring, water and soil management, and mining and mineral exploration).

From the 34 Initiatives collected, a total of $\mathbf{3 0 9}$ stakeholders were identified. Major conclusions are:

- Countries with the highest numbers of stakeholders are:: United Kingdom, Germany, Italy, Spain and France.

- Types of organizations with the major number of stakeholders are: universities, private companies and scientific research institutions.

- There are 21 initiatives that produce datasets and/or webservices (Figure 3 ).

- 15/26 research initiatives, $14 / 23$ networking initiatives and $10 / 16$ of research and networking activities produce datasets and/or web-services (Figure 3).

- Geospatial resources that present the potential to be tagged GEOSS Data Core are made available by 15 initiatives (Figure 4).

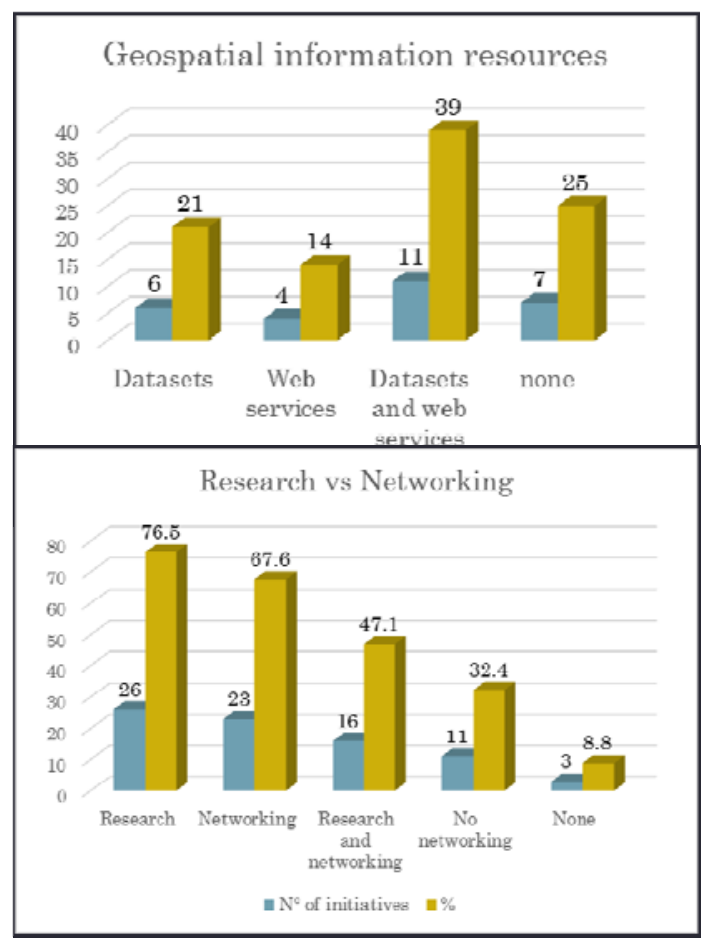

Figure 3.21 initiatives that produce datasets and/or webservices

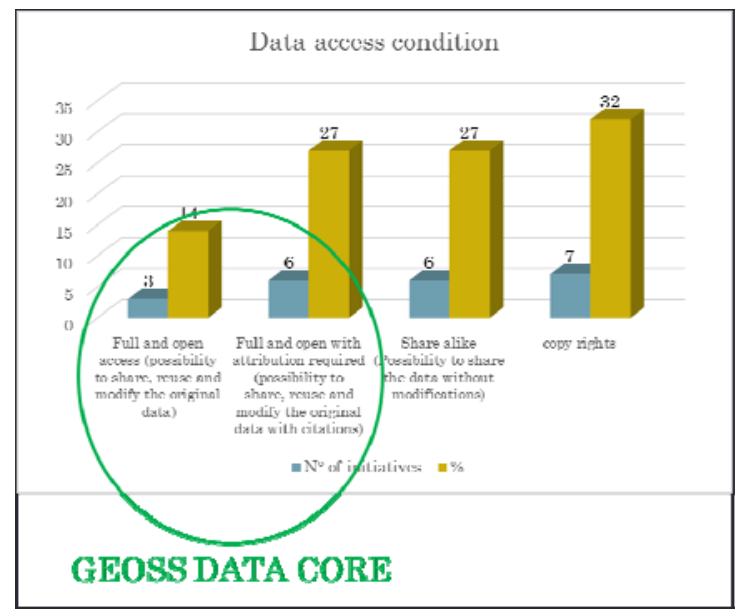

Figure 4. Geospatial resources that present the potential to be tagged GEOSS Data Core are made available by 15 initiatives
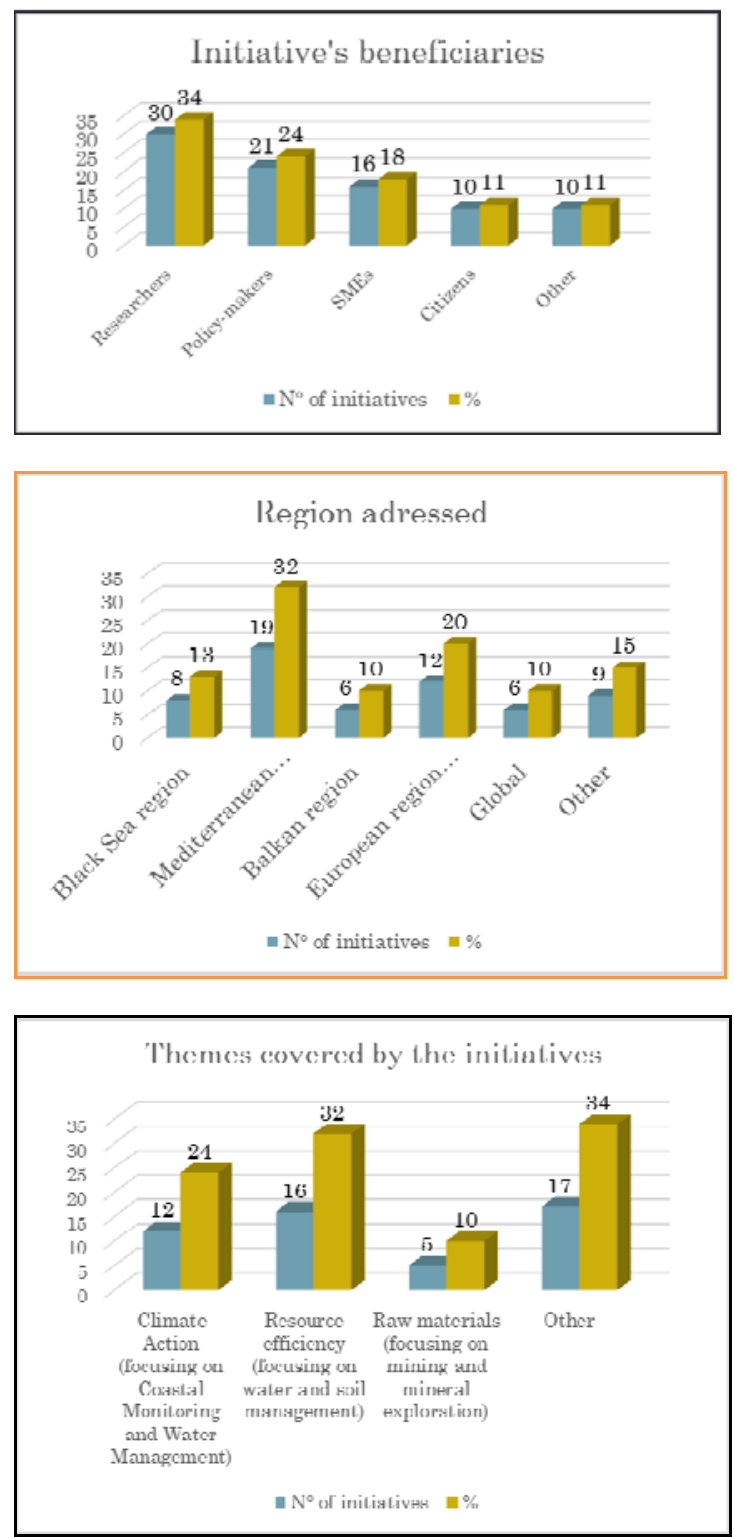

Figure 5. Other major conclusions 
IASON is also developing a visualization toolkit aimed to facilitate the gap analysis in terms of societal and economic needs and to foster the strategic cooperation between stakeholders in the Mediterranean and Black Sea regions. The visualization toolkit is conceived as a tool for performing a visual analysis of the information available about stakeholders and initiatives of interest for the Mediterranean and Black Sea regions Based on examples of use in social media (e.g. LinkedIn) to highlight existing links, a preliminary decision was on adopting graphs for visualization. In a graph, only nodes and edges exist; nodes represent relevant entities, and edges represent existing links between entities. Colors can be used to differentiate nodes and entities based on their additional attributes.

A further decision was to provide different ways for interacting with graphs. The former is a full manipulation through a desktop tool. Gephi [https://gephi.org/] was chosen based on its capabilities, extensibility through plugin, and free/open-source distribution. The second way is a limited manipulation, but available directly through the Web without an plugin or extension. Through an automatic procedure, the IASON Permanent Networking Facility (PNF) is explored extracting information:

a) relevant entities:

- Initiatives

- Beneficiaries

- Geographical areas

- Stakeholders

- Pillars

b) existing links:

- Initiative $-($ benefits $) \rightarrow$ Beneficiary

- Initiative - ( covers $) \rightarrow$ Geographical area

- Initiative - ( focuses on $) \rightarrow$ Pillar

- Stakeholder - ( belongs to ) $\rightarrow$ Geographical area

- $\quad$ Stakeholder - ( has interest in $) \rightarrow$ Pillar
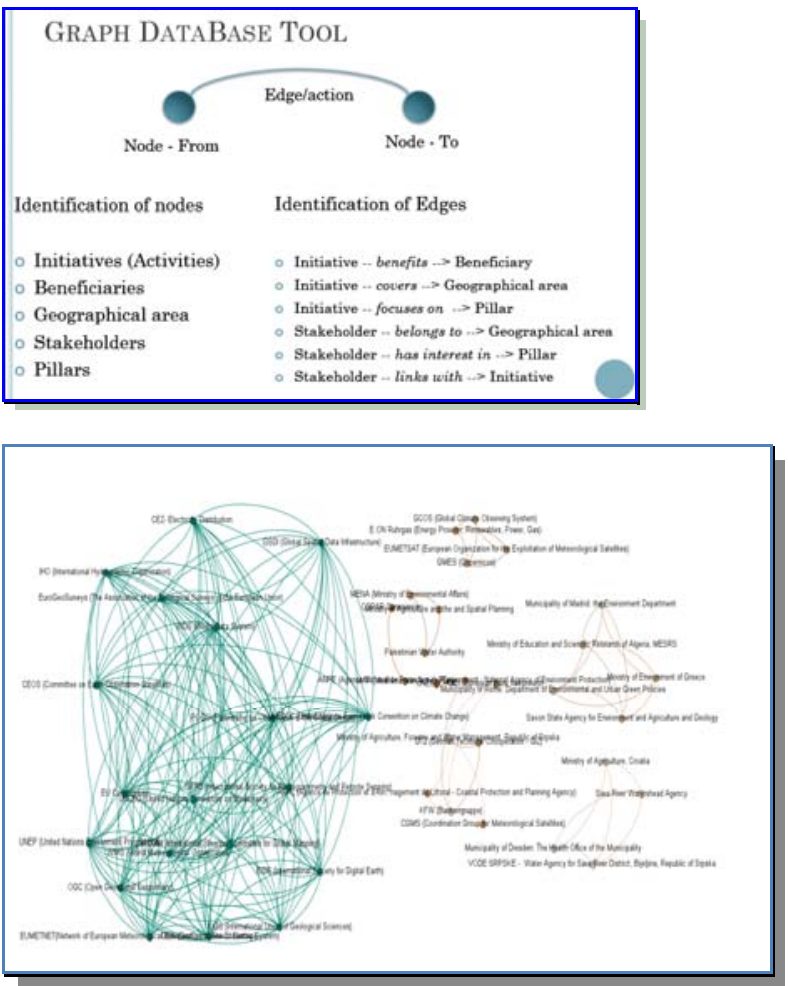

Figure 6. An example of Network Analysis

\subsection{IASON Virtual Meeting Place}

IASON Virtual Meeting Place (IVMP) constitutes a virtual meeting place that provides tools and support for communication between stakeholders, research institutes, and end-users. It enables sharing of training and teaching materials and supports users in integrating existing content or creating new resources. In synchronization with IASON project's main objectives IVMP aims to maximize the visibility of resources that have been already created in previous European projects and the benefits one can obtain from them.

IASON Virtual Meeting Place has been developed based on eGLE Platform and fully benefits from all its functionality and flexibility, empowering efficient twinning capabilities of previously developed materials and tools. The resources displayed in IVMP can be:

- created directly in IASON Virtual Meeting Place using eGLE capabilities

- created with external tools and updated into IASON Virtual Meeting Place

- created and already published in another IASON repository but presented also on IVMP

Created with extensibility in mind, eGLE Platform is based on a distributed architecture (see Figure 4) that enables out-of-thebox connectivity for standardized resources like OGC Web Services, HTTP accessible resources etc. At the same time, new connectors (named tools) can be created and included to manage the communication process with customized APIs. After registration into the platform, the use of any connector is very simple and straightforward: through drag-and-drop interactions any author can integrate the desired tools into his/her resources.

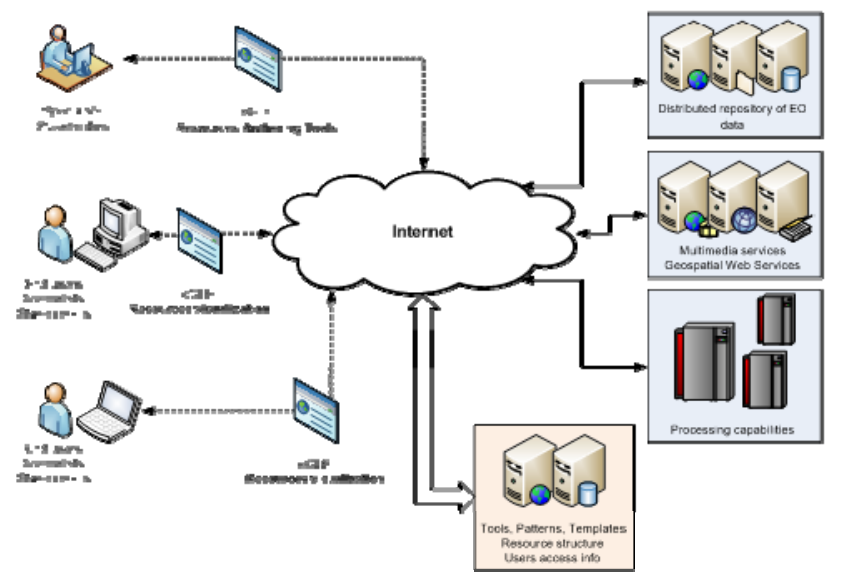

Figure 7. eGLE Platform architecture

Through eGLE, all the authors have the ability to easily reuse resources created in previous European projects with minimal modifications and effort. They can connect processing results, available web services, remote data repositories, etc. in the same material, allowing the visitors to visualize all the information in a unitary and coherent manner. Furthermore, if the provided functionalities allow, the visitors can dynamically interact with the exposed APIs through eGLE tools (interrogate web services, design and launch processing requests on GRID or Cloud, etc.). 
For increased visibility, improved flexibility and efficiency, IASON Virtual Meeting Place (IVMP) aims to enable access to all the public resources available in IASON projects through a single portal. This will enable all the VMP users to consult the entire database of resources in a single place, encouraging a more coherent approach in data visualization, extraction and analysis.

Our purpose has been to obtain a unitary approach for all these distributed sources without replicating the data, creating a more complex management mechanism or replacing the already existing resources management systems.

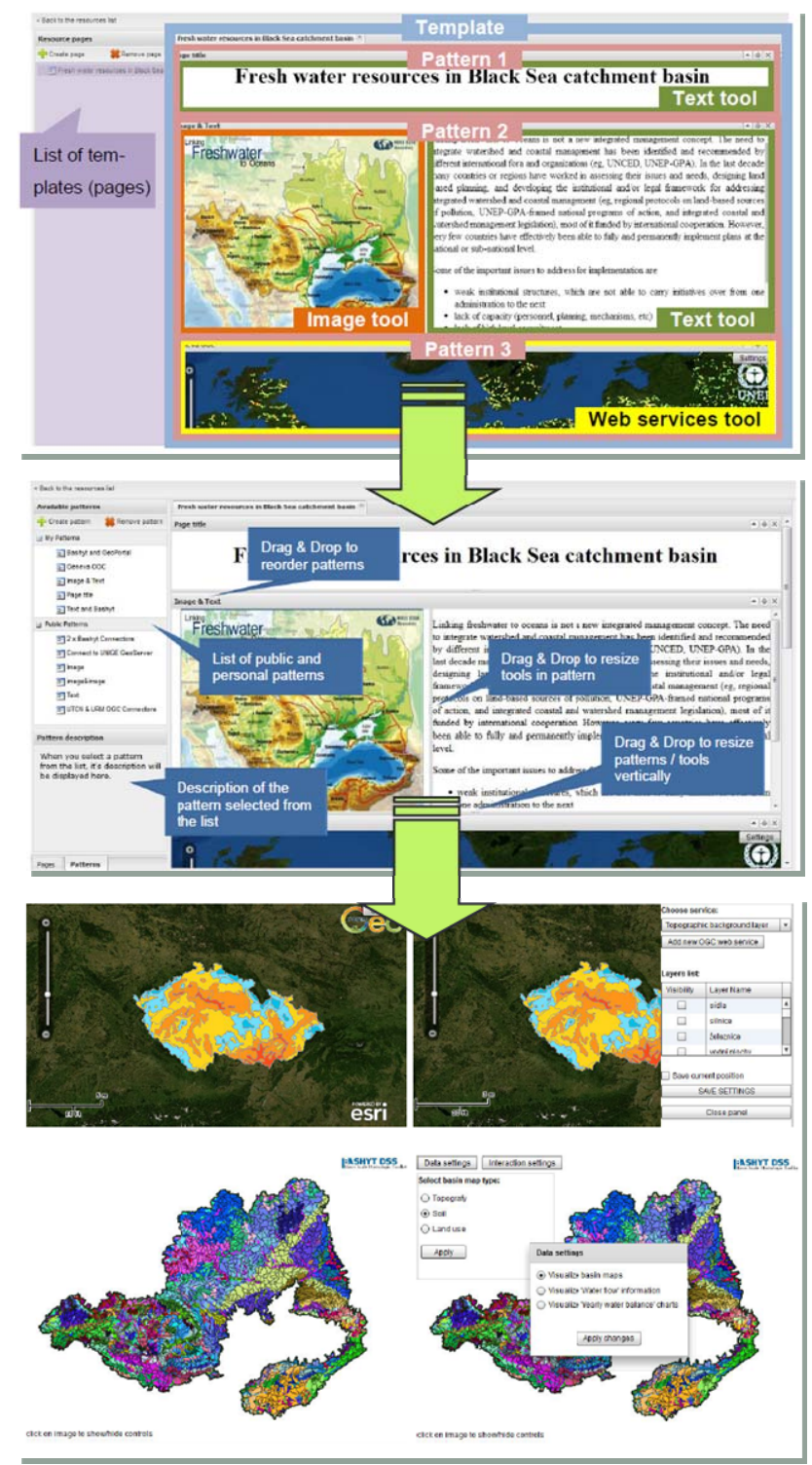

Figure 8. eGLE training resource visual structure - Pattern management and visual formatting - Example of tools configuration interfaces: OGC web services (top), dedicated Bashyt API (bottom)

Because the dynamic of the included resources can generate a different number of changes at different time intervals, the synchronization of the Virtual Meeting Place with external repositories can become very difficult. As a result we have decided to dynamically include the available resources from external repositories on the fly, at the display time, through requests sent toward specific REST APIs hosted at distributed repositories locations.

The development of new materials in IASON VMP is a process that can be completed by registered users that have the necessary knowledge in Earth Observation domain. Due to the support of eGLE interface, technical knowledge is not required, the aggregation and configuration of the available tools being carried out through simple and intuitive visual interfaces.

IASON VMP [http://cgis.utcluj.ro/iason-vcenter/] provides to visitors a short introductory page, a list of available resources and a restricted section reserved to registered members (that are also content creators). All the public resources, from the internal database of Virtual Meeting Place or from remote repositories are freely accessible to all the visitors, encouraging data exchange between interested parties.

In conclusion, the IASON VMP is a simple way of accessing diverse documents and tools available for the IASON related community of specialists. Actually VMP publishes documents from IASON Portal and remotely linked documents, and training and teaching materials already created by eGLE Platform.

The Earth Science specialists may develop themselves new training and teaching materials by using interactively the eGLE tools.

\subsection{Sustainable Funding toolkit}

A financially sustainable organisation is an organisation that can steadily support and deliver its work, capitalizing on changing markets and funding environments. Sustainability therefore, is not achieved by relying on a large grant or constant cash flows from private and public contributors. Sustainability requires constant and systematic planning and training together with a thorough knowledge of funding availability and what skills might be needed to access and manage these funds. The specific objectives of these activities are:

- To map funding opportunities within international context and beyond FP7

- To provide practical ideas and support for achieving research funding within the international context

- To perform a gap analysis on existing research and innovation national agendas taking under consideration EU priorities within Horizon2020.

- Liaise with relevant regional institutions and initiatives.

Identifying funding organizations and funding programmes is a crucial task for IASON, not only for the needs of the project, but also for other future actions and networking beyond the project boundaries and life time. The collection of information regarding funding is a fundamental action for capacity building and sustainability activities in the Mediterranean and Black Sea regions. The ability of accessing an existing database of funding organizations and institutes along with ability to enter information in the database would great facilitate these actions. Therefore it was decided to build a funding organizations and programmes component in the IASON PNF.

This component is composed of two parts: the funding organizations and institutes DB and the component GUI. The funding organizations and institutes is a database containing all the information about funding organizations and institutes and programmes relevant to the three pillars of the Horizon 2020 
challenge 5: climate action, resource efficiency, and raw materials with respect to Earth Observation applications, covering not only the two geographical regions (Mediterranean and Black Sea) addressed by IASON but also funding organizations that are active globally, in the Balkan region, and Europe. Under this perspective the DB can be considered as an element of a more general Capacity building and sustainable funding system.

It is noteworthy that, being aware of similar initiatives carried out by projects running in parallel and with different objectives (such as EOPOWER) or covering different geographical regions (such as SUSTAIN EU-ASEAN for South-East Asia, and ENSOCIO-LA for Latin America), the IASON project decided to take into account the need of interoperability between different Capacity Building systems.

A specific Technical Note [IASON TN1] was internally released to document the interoperability approach, and a joint activity with EOPOWER has been initiated in order to define the technical interoperability architecture based on a brokered architecture and on the GEONetCab ISO19115 metadata profile for capacity building resources. The interoperability of Capacity Building systems will allow enhancing search capabilities enabling users to perform queries on wider geographical areas, and to solve replication issues (for example inclusion of Balkan stakeholders which are already included in the BalkanGeoNet PNF and should also be part of the IASON PNF).

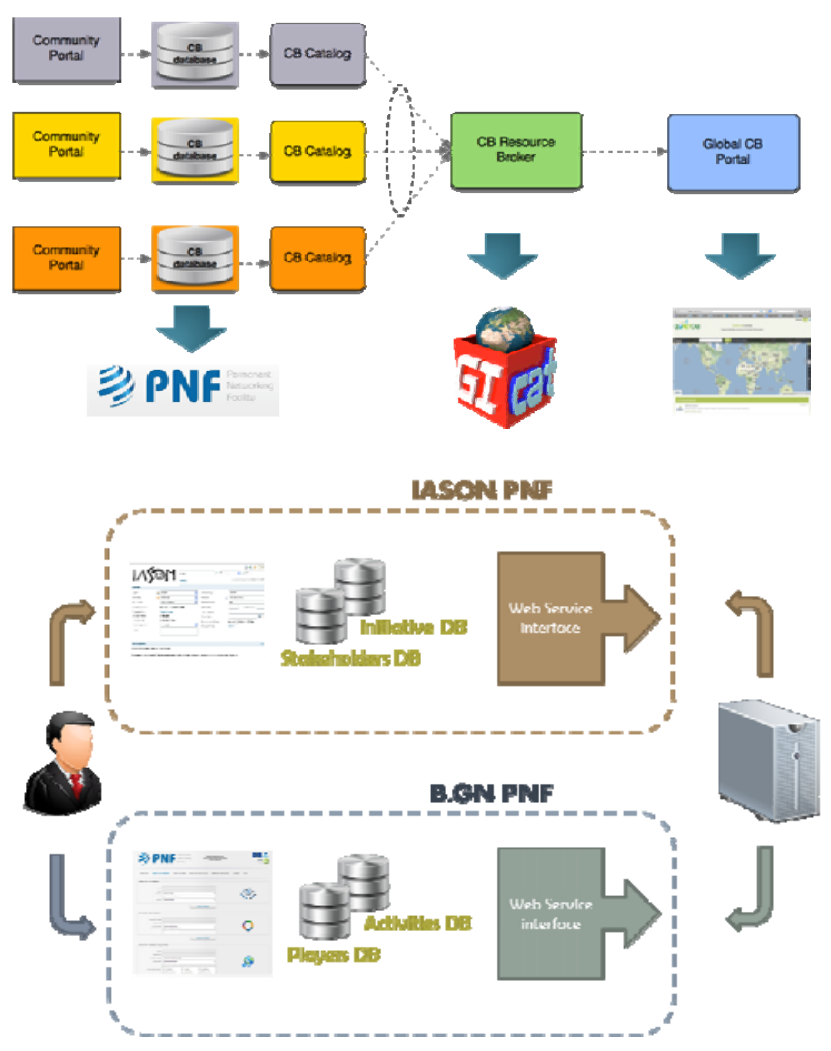

Figure 9. IASON PNF Brokered Architecture

The second macro-component of the IASON PNF is the Graphical User Interface (GUI) that, similarly to the BalkanGeoNet PNF GUI, will enable users to create, modify, delete and visualize the PNF entries. It is an essential component to keep the PNF active and up-to-date during all the duration of the project and possibly beyond.

The DB currently contains 58 funding organizations and $\mathbf{6 7}$ funding programmes. However the DB will be implemented in the IASON PNF and the IASON consortium will continue to update and insert new information during the project's lifetime.

\section{ACKNOWLEDGEMENTS}

IASON project [www.iason-fp7.eu] is supported by EU FP7 Grant Agreement No: 603534 as Coordination Action, under the Work Program Topic: ENV.2013.6.5-4, Knowledge platforms, networking and uptake of research results for strengthened international R\&I cooperation, with a duration: 24 months, starting $01 / 06 / 2013$. The project is been coordinated by the author.

\section{REFERENCES}

Dorian Gorgan, Teodor Ştefănuț and Victor Bâcu. Grid Based Training Environment for Earth Observation. Proceedings of Advances in Grid and Pervasive Computing, 4th International Conference, GPC 2009, Geneva, Switzerland, May 4-8, 2009, pp. 98-109..

Dowman, I. and Murai, S. 2008. International cooperation and capacity development, in ISPRS Book series, Vol. 7, "Advances in Photogrammetry, Remote Sensing and Spatial Information Sciences; 2008 ISPRS Congress Book", Zhilin Li; Jun Chen; Emmanuel Baltsavias (Edts), CRC Press, Taylor \& Francis Group, ISBN: 978-0-415-47805-2 (hbk), ISBN: 978-0203-88844-5 (ebook)

ESA, 2009, The Earth Observation Handbook, Online Database, http://www.eohandbook.com/

Li, S. 2008. Web mapping/GIS services and applications, in ISPRS Book series, Vol. 7, "Advances in Photogrammetry, Remote Sensing and Spatial Information Sciences; 2008 ISPRS Congress Book", Zhilin Li; Jun Chen; Emmanuel Baltsavias (Edts), CRC Press, Taylor \& Francis Group, ISBN: 978-0-41547805-2 (hbk), ISBN: 978-0-203-88844-5 (ebook).

Petcu, Dana, Silviu Panica, M. Frîncu, M. Neagul, D. Zaharie, G. Macariu, Dorian Gorgan and Teodor tefănu . Experiences in building a Grid-based platform to serve Earth observation training activities. Computer Standards \& Interfaces, Vol. 34 (6), pp. 493-508, 2012.

Ştefănuț, Teodor, Victor Bâcu and Dorian Gorgan. eLearning Lesson Development and Execution Based on gProcess Workflow Description Platform and eGLE E-learning Platform. HiPerGRID - 3rd International Workshop on High Performance Grid Middleware. Bucarest, Romania, 28 May 2009, pp. 431436.

Ştefănuț, Teodor, George Popescu and Dorian Gorgan. Elearning platform for educational resources repurposing in Earth Observation. 12th International Symposium on Symbolic and Numeric Algorithms for Scientific Computing, SYNASC 2010; Timisoara; 23 - 26 September 2010, pp. 308-314.

United Nations Department of Economic and Social Affairs, Division of Sustainable Development. 2004. Plan of Implementation of the World Summit on Sustainable 
Development, Johannesburg. (see especially pages 31-33). http://www.un.org/esa/sustdev/documents/WSSD_POI_PD

\section{Reports}

[BGN D6.1] BalkanGeoNet Consortium, "Permanent Networking Facility - PNF", deliverable D6.1. Available at: http://www.balkangeo.net/images/stories/deliverables/BalkanG EONet_D6.1.pdf

[BGSP] G. Giuliani, P. Lacroix, "GEOSS in practice", http://www.unige.ch/sig/enseignements/GeossInPractice.html

[EGIDA] S. Nativi, H.P. Plag, P. Mazzetti (edited by) "Towards a Sustainable Geoss. (Global Earth Observation System of Systems) - Some Results of the Egida Project”, AION, 2013.

[EGIDA D4.1] EGIDA Consortium, "Analysis of initiatives relevant for the GEOSS S\&T objectives", deliverable D4.1. Available at http://egidaproject.eu/images/documents/analysis.pdf

[EGIDA D4.8] EGIDA Consortium, "The EGIDA Methodology - Final version", deliverable D4.8. Available at: http://www.egida-

project.eu/images/documents/Deliverable_4.8.pdf

[GEO CB] GEO Capacity Building Committee. http://www.earthobservations.org/ag_cbc.shtml

[GEONETCAB CBS] M. Noort. "GEONetCab Capacity Building Strategy". Available at: http://www.itc.nl/library/papers_2012/general/noort_capacity.p df

[H2020 SC5] European Commission, "HORIZON 2020 WORK PROGRAMME 2014 - 2015 12. Climate action, environment, resource efficiency and raw materials", European Commission Decision C (2013)8631 of 10 December 2013

[IASON D2.1] P. Mazzetti (edited by), "Report on Existing Thematic Networks (in the three focal areas) in the Mediterranean Region", deliverable D2.1.

[IASON D2.2] P. Mazzetti (edited by), "Report on Existing Thematic Networks (in the three focal areas) in the Black Sea Region", deliverable D2.2. Available at: http:/www.iasonfp7.eu/index.php/en/home-eng/public-deliverableseng? download $=20$ :d2-2-report-on-existing-thematic-networksin-the-three-focal-areas-in-the-black-sea-region

[IASON D2.3] S. Fusani (edited by), "Report on Finished and Ongoing research efforts (in the three focal areas) in the Mediterranean Region", deliverable D2.3. Available at: http://www.iason-fp7.eu/index.php/en/home-eng/publicdeliverables-eng?download=21:d2-3-report-on-finished-andongoing-research-efforts-in-the-three-focal-areas-in-themediterranean-region

[IASON D2.4] N. Bonora (edited by), "Report on Finished and Ongoing research efforts (in the three focal areas) in the Black Sea Region", deliverable D2.4. Available at: http://www.iasonfp7.eu/index.php/en/home-eng/public-deliverableseng?download $=22$ :d2-4-report-on-finished-and-ongoingresearch-efforts-in-the-three-focal-areas-in-the-black-sea-region
[IASON TN1] P. Mazzetti, B. Antic, R. Andricevic, M. Massabò. "Architectural Framework for a Capacity Building System of System". IASON Technical Note, 2013

[OBSERVE CARAVAN] OBSERVE Consortium, "Caravan Workshops", OBSERVE Web site, http://www.observefp7.eu/index.php?option $=$ com_content $\&$ view $=$ article \&id $=162 \&$ Itemid $=248$

[PNF] BalkanGEONet Consortium, "Permanent Networking Facility", http://balkangeonet.unist.hr/

\section{Projects}

OBSERVE http://www.observe-fp7.eu/

EGIDA http://www.egida-project.eu/

BalkanGeoNet http://www.balkangeo.net/

GEONetCab http://geonetcab.espace-dev.fr/

enviroGRIDS http://envirogrids.net/

PEGASO http://www.pegasoproject.eu/

IMPACTMIN http://www.impactmin.eu/

GiSHEO, On demand Grid services for high education and training in Earth Observation, ESA-PECS project. http://gisheo.info.uvt.ro/.

BASHYT: the CWE Framework of the BSC-OS Portal. http://www.envirogrids.net/download_area/batumi/30October20 12/workshop2-BASHYT-Cau_Batumi-georgia.pdf

BSC-OS, Black Sea Catchment Observation System, http://portal.envirogrids.net/ 